\title{
Enxertia, produção e qualidade de tomateiros cultivados em ambiente protegido
}

\author{
Grafting, production and quality of tomato growth in protected environment
}

\section{Rodolfo Araujo Loos ${ }^{\mathrm{I}}$ Fabiano Ricardo Brunele Caliman' Derly José Henriques da Silva ${ }^{\mathrm{I}}$}

\section{- NOTA -}

\section{RESUMO}

Com o objetivo de verificar os efeitos da enxertia na produção e qualidade de tomateiros cultivados em ambiente protegido, conduziu-se um experimento em Viçosa, Minas Gerais (MG). Seis tratamentos foram avaliados no delineamento em blocos casualizados, com três repetições, resultantes da combinação de duas cultivares de tomate 'Débora' $e$ 'Sta. Clara', enxertadas sobre os porta-enxertos 'Anchor $T$ ' $e$ ' $B G H$ 3472', além das duas cultivares de pés francos. A enxertia foi realizada por encostia. Os tratamentos enxertados com ' $B G H$ 3472' e os pés francos Débora e Sta. Clara apresentaram as maiores produtividades comerciais. Não houve variação no teor de SST dos frutos, e o pH da polpa dos frutos foi menor nas combinações 'Anchor T'/Sta. Clara e 'BGH 3472'/Débora. Observou-se maior ATT nos frutos de Débora e menor nos frutos de Sta. Clara. A relação SST/ATT foi maior nos frutos da combinação 'Anchor T'/Sta. Clara, comparados aos frutos das combinações 'BGH 3472'/Débora e 'Anchor T'/Débora.

Palavras-chave: Lycopersicon esculentum Mill., portaenxerto, produtividade, qualidades organolépticas.

\section{ABSTRACT}

In order to check the effects of grafting in the production and quality of tomato grown in unheated greenhouse, an experiment was conducted in Viçosa, Minas Gerais State, Brazil. Six treatments were evaluated in randomized block design with three replications, resulting from the combination of two tomato cultivars Débora and Sta. Clara, grafted on two rootstocks 'Anchor $T$ ' and 'BGH 3472' in addition of the two ungrafted cultivars. The grafting method utilized was used. The treatments with the rootstock 'BGH 3472' and the cultivars 'Débora' and 'Sta. Clara' presented greatest commercial yields. There was no change in the content of SST.
Fruit $\mathrm{pH}$ was smaller at the combinations 'Anchor T'/Sta.Clara and 'BGH 3472'/Débora Clara. It was observed greater ATT in the pulp of the fruits of Débora and smaller in the fruits of Sta. Clara. SST/ATT ratio was greater in fruits of the combination 'Anchor T'/Sta.Clara when compared with the fruits of the combinations between BGH 3472/Débora and BGH and 'Anchor T'/Débora.

Key words: Lycopersicon esculentum Mill., rootstock, yield, solid soluble content.

A produção e a qualidade de frutos de tomate, em condições protegidas ou não, são afetadas por diferentes fatores, seja de natureza biótica, como pragas e doenças, ou abiótica, como salinidade, estresse hídrico, dentre outros (GINOUX \& DAUPLÉ, 1985). A enxertia tem sido adotada como alternativa para a produção de tomate em condições desfavoráveis, como as citadas acima.

O principal objetivo ao utilizar a enxertia de hortaliças é, segundo PEIL (2003), obter resistência a doenças do solo e, portanto, possibilitar o cultivo de determinadas variedades e espécies em áreas contaminadas por patógenos. $\mathrm{O}$ porta-enxerto resistente se mantém sadio, assumindo a função de absorver água e nutrientes do solo, ao mesmo tempo em que isola a cultivar sensível do patógeno ou de condição desfavorável presente no solo.

O porta-enxerto 'Anchor T', considerado padrão de resistência à murcha bacteriana (Ralstonia

'Departamento de Fitotecnia, Universidade Federal de Viçosa (UFV). Av. P. H. Rolfs, s/n, 36570-000, Viçosa, MG, Brasil. E-mail: derly@ufv.br.*Autor para correspondência 
solanacearum), patógeno de solo causador de prejuízo às plantas de tomateiro, tem sido importante para a produção de frutos de tomate em solos contaminados. Além desse porta-enxerto, há relatos de que o acesso 'BGH 3472', do Banco de Germoplasma da UFV, uma cultivar de tomate de mesa norte-americana (Carolina do Norte) de 1970, também possa se tornar opção de porta-enxerto resistente a $\boldsymbol{R}$. solanacearum para cultivo em áreas contaminadas (SILVA, 2001 - Informe verbal),

No cultivo em ambiente protegido, é de grande interesse a utilização de materiais com resistência a patógenos de solo por ser este um dos principais problemas enfrentados pelos produtores. Entretanto, é necessário verificar se a produção e qualidade de frutos são satisfatórias na associação entre uma cultivar comercial e o acesso resistente. Nesse sentido, este trabalho teve por objetivo avaliar a utilização dos porta-enxertos Anchor T e BGH-3472 na produtividade e qualidade de frutos de tomateiro das cultivares 'Sta. Clara' e 'Débora' em ambiente protegido, independente da ocorrência de doenças.

O trabalho foi realizado no Setor de Olericultura, da Universidade Federal de Viçosa (UFV), de janeiro a julho de 2001. Seis tratamentos foram estudados no delineamento em blocos ao acaso, com três repetições e quatro plantas por parcela, resultantes da combinação de duas cultivares de tomate, 'Débora' e 'Sta. Clara', enxertadas sobre dois porta-enxertos, 'Anchor T’ e 'BGH 3472', além de duas cultivares não enxertadas (testemunhas).

As mudas foram produzidas em ambiente protegido, utilizando-se bandejas de poliestireno expandido de 72 células. Foi utilizado o substrato Plantmax $^{\circledR}$. Em uma mesma célula foram semeadas, lado a lado, sementes do porta-enxerto e do enxerto. A irrigação foi realizada diariamente, com regador manual de crivo fino. Quando as mudas apresentavam quatro folhas verdadeiras, foi realizada a enxertia por encostia (ODA, 1995). Para a união das duas plantas, utilizou-se um prendedor curvo para enxerto de pepino. Depois de 10 dias, foi realizado um corte no caule do enxerto abaixo do ponto de enxertia e dois dias após o corte foi retirado o clipe. Quatro dias após o ‘desmame’, as mudas foram transplantadas para o solo do local definitivo, num ambiente protegido. As mudas foram transplantadas no espaçamento de $1,0 \times 0,6 \mathrm{~m}$, sendo tutoradas no sistema vertical com fitilho e conduzidas com uma haste e seis cachos. A adubação de plantio consistiu na aplicação de nutrientes, conforme sugestão de RIBEIRO et al. (1999).

Foi realizada a acaliação da porcentagem de pegamento de plantas após 30 dias do transplantio, o do atraso na formação das mudas devido à enxertia, da produção comercial classificada e da produção total de frutos. Nas colheitas, os frutos sadios foram contados, pesados e classificados de acordo com o maior diâmetro transversal do fruto, segundo norma adaptada do Ministério da Agricultura (Portaria n ${ }^{\circ} 553$ MA, publicado no DOU de 19/09/95).

Para a avaliação das características de qualidade, foram colhidos cinco frutos no início da maturação (estágio breaker), em cada uma das parcelas, sendo posteriormente submetidos aos processos analíticos de acordo com a metodologia do Instituto Adolf Lutz (PREGOLATO \& PREGOLATO, 1985). Foram avaliados: Sólidos solúveis totais (SST, ${ }^{\circ} \mathrm{BRIX}$ ); acidez total titulável (ATT, \% de ácido cítrico) e pH da polpa dos frutos. Utilizou-se a relação SST/ATT como um indicador do sabor dos frutos, como descrito por KADER et al. (1978). As características avaliadas foram submetidas à análise de variância e ao teste de média (Tukey a 5\% de probabilidade de erro).

Verificou-se $100 \%$ de pegamento de plantas após 30 dias do transplantio em todos os tratamentos (Tabela 1), evidenciando que os porta-enxertos não

Tabela 1 - Pegamento das mudas 30 após o transplantio (PMAT), produtividade classificada, comercial, total e perdas de frutos de tomateiros 'Santa Clara' e ‘Débora', enxertados nos porta-enxertos 'BGH 3472' e ‘Anchor T’ e de pés francos.

\begin{tabular}{|c|c|c|c|c|c|c|c|c|}
\hline \multirow{2}{*}{ Tratamento } & \multirow{2}{*}{$\begin{array}{l}\text { PMAT } \\
\text { (\%) }\end{array}$} & \multicolumn{4}{|c|}{-----------Produtividade classificada (t ha $\left.{ }^{-1}\right)$----------- } & \multirow{2}{*}{$\begin{array}{l}\text { Produtividade } \\
\text { comercial } \\
\left(\mathrm{t} \mathrm{ha}^{-1}\right)\end{array}$} & \multirow{2}{*}{$\begin{array}{l}\text { Produtividade } \\
\text { total }\left(\mathrm{t} \mathrm{ha}^{-1}\right)\end{array}$} & \multirow{2}{*}{$\begin{array}{l}\text { Perdas } \\
\left(\mathrm{t} \mathrm{ha}^{-1}\right)\end{array}$} \\
\hline & & $\begin{array}{c}\text { Pequeno } \\
(40-50 \mathrm{~mm})\end{array}$ & $\begin{array}{l}\text { Médio especial } \\
(50,1-54,8 \mathrm{~mm})\end{array}$ & $\begin{array}{l}\text { Médio extra } \\
(54,9-60 \mathrm{~mm})\end{array}$ & $\begin{array}{l}\text { Graúdo } \\
\text { (>60mm) }\end{array}$ & & & \\
\hline Sta. Clara & 100 & $0,10 \mathrm{~A}$ & $9,89 \mathrm{CD}$ & $7,16 \mathrm{AB}$ & $50,78 \mathrm{~A}$ & $67,94 \mathrm{~A}$ & $76,68 \mathrm{AB}$ & $8,74 \mathrm{~A}$ \\
\hline Débora & 100 & $1,62 \mathrm{~A}$ & $37,65 \mathrm{AB}$ & $14,89 \mathrm{~A}$ & 10,97 B & $65,12 \mathrm{~A}$ & $70,40 \mathrm{AB}$ & $5,28 \mathrm{~A}$ \\
\hline Anchor T/Débora & 100 & 3,39 A & $22,40 \mathrm{BC}$ & 3,05 B & $5,85 \mathrm{~B}$ & $34,69 \mathrm{~B}$ & $40,48 \mathrm{AB}$ & $5,74 \mathrm{~A}$ \\
\hline Anchor T/St. Clara & 100 & $1,40 \mathrm{~A}$ & 6,06 CD & $4,10 \mathrm{AB}$ & $10,19 \mathrm{~B}$ & 21,74 B & 27,43 B & 5,69 A \\
\hline BGH 3472/Débora & 100 & $1,38 \mathrm{~A}$ & $43,00 \mathrm{~A}$ & $15,15 \mathrm{~A}$ & $12,47 \mathrm{~B}$ & $71,89 \mathrm{~A}$ & $91,61 \mathrm{~A}$ & $19,72 \mathrm{~A}$ \\
\hline BGH 3472/St. Clara & 100 & $0,38 \mathrm{~A}$ & $4,97 \mathrm{D}$ & $9,75 \mathrm{AB}$ & $49,24 \mathrm{~A}$ & $64,34 \mathrm{~A}$ & $72,72 \mathrm{AB}$ & $8,36 \mathrm{~A}$ \\
\hline CV (\%) & - & 23,2 & 19,83 & 35,3 & 27,65 & 16,68 & 16,38 & 33,8 \\
\hline
\end{tabular}

Médias não seguidas pela mesma letra na coluna diferem entre si, em nível de 5\% de probabilidade de erro, pelo teste Tukey. 
interferiram no estabelecimento das plantas. Não foi observado atraso na formação das mudas enxertadas comparadas com os pés-francos, o que possibilitou que todas as mudas fossem transplantadas simultaneamente para o local definitivo.

Os tratamentos com porta-enxerto ' $\mathrm{BGH}$ 3472' ('BGH 3472'/Débora e 'BGH 3472'/Sta. Clara) e as cultivares 'Débora' e 'Sta. Clara' de pé-franco apresentaram as maiores produtividades comerciais,

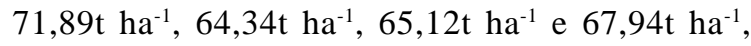
respectivamente (Tabela 1 ).

Esperava-se que o 'Anchor T', híbrido comercial japonês para porta-enxerto, proporcionasse maior produtividade, considerando sua ampla difusão como porta-enxerto. Todavia, o acesso 'BGH 3472', uma cultivar antiga, possibilitou, em associação com 'Sta. Clara' e 'Débora', maior tamanho e número de frutos.

As produtividades de 'Sta. Clara' e 'Débora' enxertadas em 'Anchor T' foram, respectivamente, três e duas vezes inferiores aos pés-francos. Vale salientar que o fato de o experimento não ter sido conduzido em solo comprovadamente infectado, e não havendo ocorrência de patógenos, os porta-enxertos não puderam expressar a sua resistência, que poderia favorecer o aumento de produtividade sob condições de ocorrência de doenças. Como não houve diferença entre as cultivares com ou sem enxertia no 'BGH-3472', provavelmente por boa compatibilidade entre o enxerto e porta-enxerto, torna-se possível a utilização do acesso 'BGH-3472' como alternativa para o cultivo do tomateiro em solos contaminados, sem que haja efeito negativo na produção.

De acordo com os resultados das análises de variância para qualidade de frutos, houve significância de efeito de tratamento para todas as características, com exceção do teor de SST (Tabela 2), que variou de 3,34 ${ }^{\circ}$ Brix a 4,26 ${ }^{\circ}$ Brix, valores esses semelhantes aos observados por CARDOSO et al. (2006), os quais avaliaram a combinação do porta-enxerto 'Hawaii 7996' com os enxertos ‘Sta. Clara’, ‘Santa Cruz Kada’ e ‘Débora Plus' e obtiveram teor de SST de 4,30 ${ }^{\circ}$ Brix, 3,95 Brix e $4,70^{\circ}$ Brix, respectivamente. As cultivares 'Débora'e 'Sta. Clara', quando enxertadas em 'BGH 3472' e não enxertadas, apresentaram os maiores valores de $\mathrm{pH}$. 'Sta. Clara' enxertada em 'Anchor T' apresentou o menor valor de $\mathrm{pH}$ (Tabela 2). $\mathrm{O} \mathrm{pH}$ da polpa dos frutos avaliados no presente trabalho variou de 3,40 a 4,26 , valores ligeiramente inferiores aos resultados de CARDOSO et al. (2006), os quais variaram de 4,04 a 4,30, em frutos de plantas de tomate enxertadas no porta-enxerto 'Hawaii 7996'.

Não foram observadas diferenças significativas em relação à ATT dos frutos quando as cultivares 'Sta. Clara' e 'Débora' foram enxertadas em 'Anchor T' e 'BGH 3472', indicando não haver efeito do porta-enxerto na acidez dos frutos destas cultivares. As cultivares 'Débora' e 'Sta. Clara', como pés francos, apresentaram, respectivamente, maior e menor ATT (Tabela 2).

No tocante à relação SST/ATT, foi observado que a combinação 'Anchor T'/'Sta. Clara' apresentou valor superior à dos frutos da combinação 'BGH 3472'/Débora e 'Anchor T’/Débora (Tabela 2). CARDOSO et al. (2006) avaliaram a combinação do porta-enxerto ‘Hawaii 7996' com ‘Santa Clara', ‘Santa Cruz Kada’ e ‘Débora Plus’ e obtiveram relação SST/ ATT de 15,4, 14,6 e 13,2, respectivamente.

$\mathrm{O}$ acesso BGH 3472, utilizado como portaenxerto, não alterou as produtividades comerciais das cvs. 'Sta. Clara' e 'Débora'. Entretanto, houve redução de produtividade quando se utilizou o ‘Anchor T’ como porta-enxerto. A utilização de combinações de enxerto e porta-enxerto não alterou a qualidade dos frutos das cvs. 'Sta. Clara' e 'Débora' no que se refere ao teor de $\mathrm{SST}$, pH, ATT e à relação SST/ATT. A associação 'BGH 3472'/Sta. Clara apresentou-se promissora por produzir frutos graúdos, com boa relação SST/ATT e boa reação de compatibilidade.

Tabela 2 - Resultados de Sólidos solúveis totais (SST), pH, acidez total titulável (ATT) e relação sólidos solúveis totais/acidez total titulável (SST/ATT) de frutos de ‘Santa Clara' e ‘Débora', enxertados nos porta-enxertos 'BGH 3472' e ‘Anchor T’ e de pés francos.

\begin{tabular}{lcccc}
\hline Tratamentos & SST ( ${ }^{\circ}$ Brix) & pH & ATT & SST/ATT \\
\hline Sta. Clara & $3,35 \mathrm{~A}$ & $4,26 \mathrm{~A}$ & $0,31 \mathrm{~B}$ & $0,35 \mathrm{AB}$ \\
BGH 3472/Sta. Clara & $3,75 \mathrm{~A}$ & $4,24 \mathrm{~A}$ & $\mathrm{AB}$ \\
Anchor T/Sta. Clara & $4,22 \mathrm{~A}$ & $3,40 \mathrm{~B}$ & $0,36 \mathrm{AB}$ & $10,58 \mathrm{AB}$ \\
Débora & $4,27 \mathrm{~A}$ & $4,15 \mathrm{~A}$ & $0,44 \mathrm{~A}$ & $9,70 \mathrm{AB}$ \\
BGH 3472/Débora & $3,61 \mathrm{~A}$ & $4,15 \mathrm{~A}$ & $0,42 \mathrm{AB}$ & $8,60 \mathrm{~B}$ \\
Anchor T/Débora & $3,75 \mathrm{~A}$ & $3,97 \mathrm{AB}$ & $0,42 \mathrm{AB}$ & $8,92 \mathrm{~B}$ \\
CV (\%) & 12,05 & 5,02 & 10,94 & 9,05 \\
\hline
\end{tabular}

Médias não seguidas pela mesma letra na coluna diferem entre si, em nível de 5\% de probabilidade de erro, pelo teste de Tukey. 


\section{AGRADECIMENTOS}

Ao Conselho Nacional de Desenvolvimento Científico e Tecnológico (CNPQ), pelo apoio financeiro.

\section{INFORME VERBAL}

SILVA, D. J. H. Comunicação pessoal. 2001. Curador do Banco de Germoplasma de Hortaliças da Universidade Federal de Viçosa (BGH-UFV). Universidade Federal de Viçosa Departamento de Fitotecnia, Av. P. H. Rolfs, s/n - 36570-000 - Viçosa - MG. E-mail: derly@ufv.br

\section{REFERÊNCIAS}

CARDOSO, S.C. et al. Qualidade de frutos de tomateiro com e sem enxertia. Bragantia, v.65, n.2, p.269-274, 2006.

RIBEIRO, A.C. et al. (Eds). Recomendação para o uso de corretivos e fertilizantes em Minas Gerais. 5.aprox. Viçosa: UFV, 1999. 359p.
GINOUX, G.; DAUPLÉ, P. Greffe par perforation latérale de l'aubergine et de la tomate. P.H.M. Revue Horticole, n.253, p.29-34, 1985.

KADER, A.A. et al. Composition and flavor quality of fresh market tomatoes as influenced by some postharvest handling procedures. Journal of American Society for Horticulture Science, v.113, n.5, p.742-745, 1978.

ODA, M. New grafting methods for fruit bearing vegetables in Japan. Japan Agricultural Research Quartely, v.29, p.187194, 1995

PEIL, R.M. A enxertia na produção de mudas de hortaliças. Ciência Rural, v.23, n.6, p.1169-1177, 2003.

PREGOLATO, W.; PREGOLATO, D.P. Normas snalíticas do Instituto Adolfo Lutz - Métodos químicos e físicos para análise de alimentos. 3.ed. São Paulo: IAL, 1985. V.1, 533p. 